\title{
Cold-Cracking Assessment in AA7050 Billets during Direct-Chill Casting by Thermomechanical Simulation of Residual Thermal Stresses and Application of Fracture Mechanics
}

\begin{abstract}
M. LALPOOR, D.G. ESKIN, and L. KATGERMAN
Thermally induced strains and stresses developed during direct-chill (DC) semicontinuous casting of high strength aluminum alloys can result in formation of micro-cracks in different locations of the billet. Rapid propagation of such micro-cracks in tensile thermal stress fields can lead to catastrophic failure of ingots in the solid state called cold cracking. Numerical models can simulate the thermomechanical behavior of an ingot during casting and after solidification and reveal the critical cooling conditions that result in catastrophic failure, provided that the constitutive parameters of the material represent genuine as-cast properties. Application of fracture mechanics, on the other hand, can help to derive the critical crack length leading to failure. In the present research work, the state of residual thermal stresses was determined in an AA7050 billet during DC casting by means of ALSIM5. Simulation results showed that in the steady-state conditions, large compressive stresses form near the surface of the billet in the circumferential direction, whereas in the center, the stresses are tensile in all directions. Magnitudes of von Mises effective stresses, the largest component of principal stresses and the fracture mechanics concepts, were then applied to investigate the crack susceptibility of the billet.
\end{abstract}

DOI: $10.1007 / \mathrm{s} 11661-009-0031-\mathrm{y}$

(C) The Minerals, Metals \& Materials Society and ASM International 2009

\section{INTRODUCTION}

DURING direct-chill (DC) casting of aluminum alloys, large thermal stresses develop inside the slabs (rectangular ingots) and billets (round ingots). These stresses are due to temperature gradients in the metal, and to the thermal contraction, which may result in cracking and failure. ${ }^{[1]}$ The $7 \mathrm{xxx}$ series aluminum alloys are more vulnerable to cracking mainly because of poor thermal and mechanical properties in the as-cast condition. Low thermal conductivity values compared to other aluminum alloys result in high-temperature gradients, which in turn lead to accumulation of thermal stresses with different signs and magnitudes in different locations of the billets during DC casting. A large solidification range $\left(470{ }^{\circ} \mathrm{C}\right.$ to $\left.630^{\circ} \mathrm{C}\right)$, on the other hand, makes these alloys prone to solidification cracking called hot cracking. The presence of non-equilibrium phases, with low melting points, especially at grain boundaries and interdendritic spaces provides favorable paths for crack initiation and propagation. Investigation of as-cast mechanical properties of DC-cast 7050 and 7475 alloys has shown that such alloys lose their

M. LALPOOR, Ph.D. Researcher, and D.G. ESKIN, Fellow $\mathrm{M} 2 \mathrm{i}$, are with the Materials Innovation Institute, $2628 \mathrm{CD}$ Delft, The Netherlands. Contact e-mail: mlalpoor@gmail.com L. KATGERMAN, Professor, is with the Department of Materials Science and Engineering, Delft University of Technology, Delft, 2628 CD, The Netherlands.

Manuscript submitted March 12, 2009.

Article published online October 27, 2009 ductility below $200{ }^{\circ} \mathrm{C}$ and become extremely brittle, ${ }^{[2]}$ which can make the material prone to cold cracking.

Numerical simulation of thermal stresses during DC casting of these alloys can reveal those stages and locations at which the materials susceptibility to cracking is high. The state of residual thermal stresses during DC casting have been determined by some researchers using various commercial and noncommercial finite element packages. ${ }^{[1,3-6]}$ Ludwig et al. ${ }^{[7]}$ and Boender et $a l^{[8]}$ went one step further and used the maximum principal stress and fracture mechanics to assess the critical crack size leading to catastrophic failure. For slabs (width: $1150 \mathrm{~mm}$, thickness: $360 \mathrm{~mm}$, length: $1500 \mathrm{~mm}$ ) of Al-4.5 pct $\mathrm{Cu}^{[7]}$ with the maximum principal stress $80 \mathrm{MPa}$, the critical crack size was assessed to be $8 \mathrm{~mm}$. In AA2024 slabs (width: $2000 \mathrm{~mm}$, thickness: $510 \mathrm{~mm}$, length: $2000 \mathrm{~mm}),{ }^{[8]}$ critical crack sizes appeared to be between 5 and $50 \mathrm{~mm}$ for various maximum principal stress values found in different locations. However, such study has not been performed for highly prone to cold cracking 7050 or 7075 alloys over the critical temperature range $\left(200{ }^{\circ} \mathrm{C}\right.$ down to room temperature) mainly because of lack of necessary data. On the other hand, the derived critical crack sizes can only be realistic providing that the mechanical properties and constitutive parameters used to obtain and evaluate the simulation results are extracted from the samples in the genuine as-cast condition. In the homogenized or stress-relieved states, the material shows higher plasticity ${ }^{[9,10]}$ and the constitutive parameters are different, which can lead to unreliable simulated stress and strain levels in the billet. Another issue is 
that such alloys become prone to catastrophic failure over a certain temperature range as a result of fall in the ductility mentioned previously, so the plane strain fracture toughness values must be determined over this temperature range.

In this research work the finite element package ALSIM5* has been used to compute temperatures,

\footnotetext{
*ALSIM is a casting-simulation software developed by the Norwegian Institute for Energy Technology (IFE), Kjeller, Norway.
}

thermal stresses, and strains during the starting phase and the steady-state regime in an aluminum 7050 alloy billet. An elasto-viscoplastic model ${ }^{[11]}$ was applied which assumes the strong temperature dependence of the constitutive and mechanical properties in the as-cast condition. The constitutive parameters were gained from room- and high-temperature tensile tests of the material in the as-cast condition. In the experimental part, the plane strain fracture toughness $\left(K_{\mathrm{Ic}}\right)$ of the alloy was determined from room temperature to $200{ }^{\circ} \mathrm{C}$ and was eventually applied to calculate the critical crack size using fracture mechanics concepts.

The results reported in this article will provide input for a cold cracking criterion that can be used for optimizing casting regimes in such a way that the probability of cold cracking becomes negligible.

\section{MODEL SETUP}

ALSIM5 was used for the computation of the temperature profile and stress/strain fields in the round AA7050 billet. A detailed description of the model can be found elsewhere. ${ }^{[12-15]}$ Geometry of the setup consisted of hot top, mold, water jet, bottom block, and cast domain (Figure 1). New elements with the size of $0.75 \mathrm{~mm}$ are added to the geometry at the casting speed to simulate the continuous casting conditions. So during casting, the bottom block moves downwards while new elements are added to the system, and the mold, hot top, and molten metal retain their initial position. Due to axial symmetry, only half of the billet is considered. Time-dependent thermal boundary conditions are defined to account for filling time, the air gap formation between the billet and the bottom block as well as at the billet surface, and for different heat extraction in different parts of the casting system. ${ }^{[1]}$ The process parameters are listed in Table I.

Chemical composition of the tested alloy is mentioned in Table II. Thermal as well as fluid properties of the alloy were gained from the thermodynamics database JMat-Pro provided by Corus-Netherlands (IJmuiden). The temperature dependence of the coefficient of thermal expansion, specific heat, heat conductivity, fraction solid, density, and kinematic viscosity were extracted and embedded in the model. The liquidus and nonequilibrium solidus were determined using DSC tests as $652^{\circ} \mathrm{C}$ and $470{ }^{\circ} \mathrm{C}$, respectively.

Tensile mechanical properties of as-cast 7050 samples were measured in a Gleeble-1500 thermomechanical

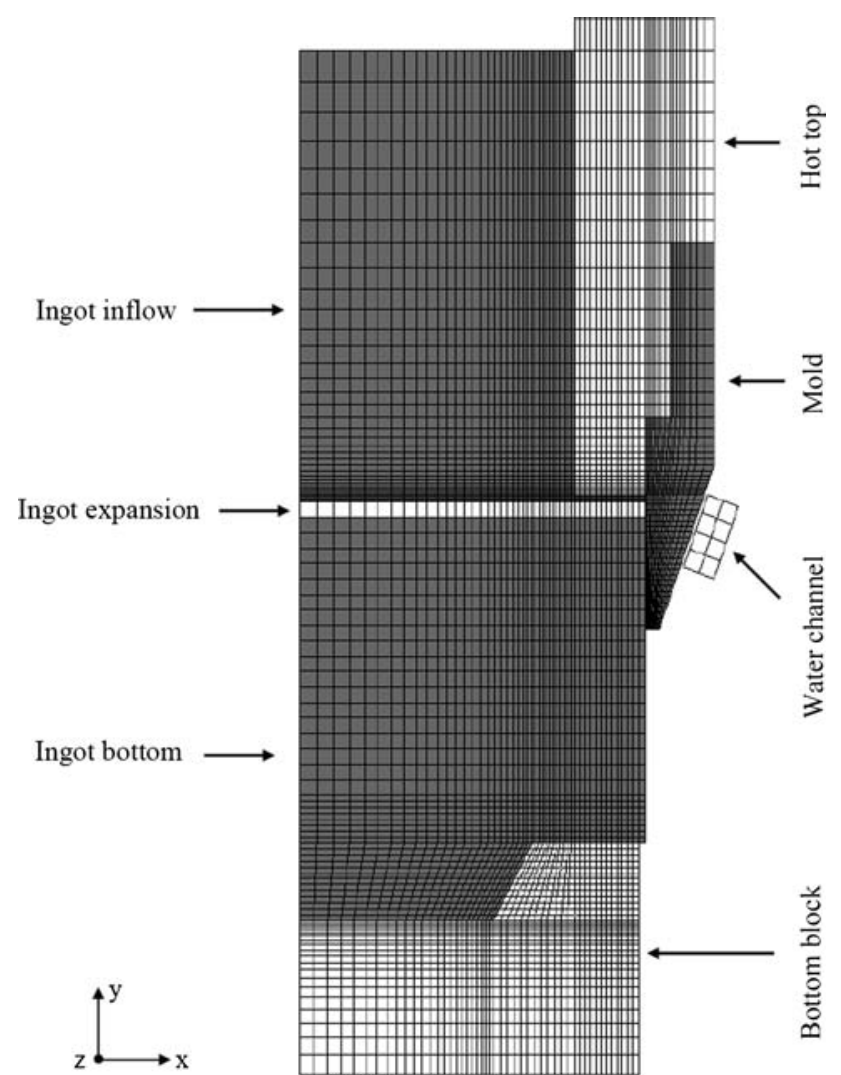

Fig. 1- Geometry of the DC-cast billet used for simulations showing the hot top, mold, bottom block, and the casting aluminum part consisting of the cast top, cast expansion, and cast bottom.

Table I. Description of Casting Process Parameters

\begin{tabular}{lr}
\hline Process Parameter & Value \\
\hline Ingot radius $(\mathrm{mm})$ & 100 \\
Final length of the billet $(\mathrm{mm})$ & 650 \\
Casting speed $(\mathrm{mm} / \mathrm{min})$ & 60 \\
Melt temperature $\left({ }^{\circ} \mathrm{C}\right)$ & 680 \\
Water flow rate $(\mathrm{L} / \mathrm{min})$ & 80 \\
Water temperature $\left({ }^{\circ} \mathrm{C}\right)$ & 15 \\
Start temperature of bottom block $\left({ }^{\circ} \mathrm{C}\right)$ & 20 \\
\hline
\end{tabular}

simulator (Dynamic Systems Inc., Poestenkill, NY) and the results are shown in Table III. ${ }^{[16]}$ In order to simulate the cooling of the billet from the solidus temperature to room temperature, the extended Ludwik equation was applied:

$$
\sigma=K(T)\left(\varepsilon_{p}+\varepsilon_{p}^{0}\right)^{n(T)}(\dot{\dot{\varepsilon}})^{m(T)}
$$

where $K(T)$ is the consistency of the alloy, $n(T)$ is the strain hardening coefficient, $m(T)$ is the strain rate sensitivity, and $\varepsilon_{p}^{0}$ is a constant equal to $0.001 .^{[17]}$ The values of $K(T), n(T)$, and $m(T)$ (Table IV) were embedded in the model using the ALSPEN fitting functions, ${ }^{[1]}$ where $n, m$, and $K$ are nonlinear functions of $T$. In ALSPEN,${ }^{[1]}$ the total viscoplastic strain has been treated as one quantity. Furthermore, a hardening parameter that accounts for the isotropic strain hardening of 
Table II. Chemical Composition of the 7050 Alloy Used for Simulations and the Cold Cracked 7475 DC-Cast Billet

\begin{tabular}{lcccccccccc}
\hline & \multicolumn{7}{c}{ Alloying Elements (Weight Percent) } \\
\cline { 2 - 10 } Alloy & $\mathrm{Zn}$ & $\mathrm{Mg}$ & $\mathrm{Cu}$ & $\mathrm{Zr}$ & $\mathrm{Cr}$ & $\mathrm{Mn}$ & $\mathrm{Ti}$ & $\mathrm{Fe}$ & $\mathrm{Si}$ \\
\hline 7050 & 6.3 & 2.42 & 2.49 & 0.098 & $<0.01$ & 0.04 & 0.03 & 0.07 & 0.04 \\
7475 & 5.46 & 2.52 & 1.74 & - & 0.20 & 0.025 & 0.057 & 0.09 & 0.06 \\
\hline
\end{tabular}

Table III. Mechanical Properties of the As-Cast 7050 Alloy Gained using Gleeble 1500 at a Strain Rate of $10^{-4} s^{-1}$

\begin{tabular}{lcccc}
\hline Temperature $\left({ }^{\circ} \mathrm{C}\right)$ & Yield Strength $(\mathrm{MPa})$ & Reduction in Area $(\mathrm{Pct})$ & Elongation $(\mathrm{Pct})$ & Young's Modulus $(\mathrm{GPa})$ \\
\hline 20 & $266.5 \pm 12.5$ & $0.4 \pm 0.1$ & 1.9 & $73 \pm 3.5$ \\
100 & $223 \pm 7$ & 0.5 & $1.4 \pm 0.1$ & $61 \pm 4.5$ \\
200 & $154 \pm 8$ & $2.5 \pm 0.2$ & $1.6 \pm 0.1$ & $34 \pm 3.5$ \\
300 & $73 \pm 2$ & $36 \pm 5$ & $3.2 \pm 0.8$ & $15 \pm 2$ \\
400 & $23 \pm 2$ & $33 \pm 3$ & $3.8 \pm 0.1$ & $5.8 \pm 0.8$ \\
\hline
\end{tabular}

Table IV. Constitutive Parameters of the 7050 Alloy; Young's Modulus (RMS-800) and Poisson's Ratio (JMat-Pro) Are Also Shown

\begin{tabular}{llcccc}
\hline Temperature $\left({ }^{\circ} \mathrm{C}\right)$ & $K(\mathrm{MPa})$ & $n$ & $m$ & $E(\mathrm{GPa})$ & Poisson's Ratio \\
\hline 20 & $774 \pm 32$ & $0.42 \pm 0.02$ & 0 & 67.9 & 0.338 \\
100 & $626 \pm 13$ & $0.38 \pm 0.01$ & 0 & 61.2 & 0.341 \\
200 & $392 \pm 11$ & $0.21 \pm 0.006$ & 0 & 57.4 & 0.346 \\
300 & $199 \pm 4.5$ & $0.11 \pm 0.007$ & $0.03 \pm 0.007$ & 53.6 & 0.352 \\
400 & $174 \pm 5$ & $0.09 \pm 0.01$ & $0.15 \pm 0.009$ & 0.358 \\
\hline
\end{tabular}

the material has been introduced to approximate the material behavior. Strain hardening is only taken into account below some certain temperature, $T_{0}$, since all the viscoplastic strain may be assumed to be generated by creep above $T_{0}$. The aforementioned hardening parameter has been defined as

$$
\alpha=\int d \alpha, \alpha=\left\{\begin{array}{cc}
d \bar{\varepsilon}_{p} & \text { when } T \leq T_{0} \\
0 & \text { otherwise }
\end{array}\right\}
$$

An onset temperature $T_{0}$, above which the strain hardening can be neglected, was determined to be $663 \mathrm{~K} .{ }^{[1]}$ Above this temperature the ALSPEN equations and cohesion model ${ }^{[18]}$ are combined. The Poisson's ratio values were gained from JMat-Pro and are shown in Table IV.

In order to assist the model, the Young's modulus of the material over the post-solidification temperature range and the plane strain fracture toughness were determined through experimental methods, which are discussed in Section III.

\section{EXPERIMENTAL RESULTS}

Rheological torsion tests were performed for 7050 as-cast samples using an RMS-800 setup in order to measure Young's modulus. The results are shown in Table IV. These results differ considerably from the ones of the tensile tests (Table II). Initial simulations showed that such differences could cause a considerable

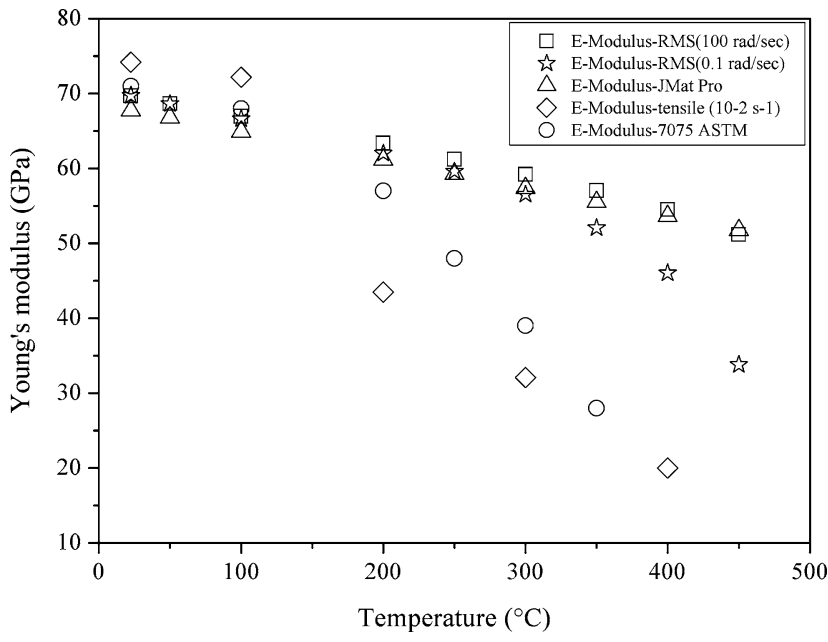

Fig. 2-Young's modulus measured through rheological torsion tests (RMS) and gained from the JMat-Pro database for AA7050 alloy. Engineering Young's modulus values measured for the AA7075 ${ }^{[19]}$ and AA7050 through tensile tests are also shown for comparison.

difference in the values of thermal stresses especially at high temperatures. Figure 2 shows the Young's modulus values of the 7050 alloy obtained through different methods, i.e., tensile tests, rheological torsion tests, and simulation results gained from JMat Pro. Below $100{ }^{\circ} \mathrm{C}$, tensile tests (ASTM results for 7075 and Gleeble for 7050) underestimate the calculated values of Young's modulus, which is mainly because of the creep. Similar 


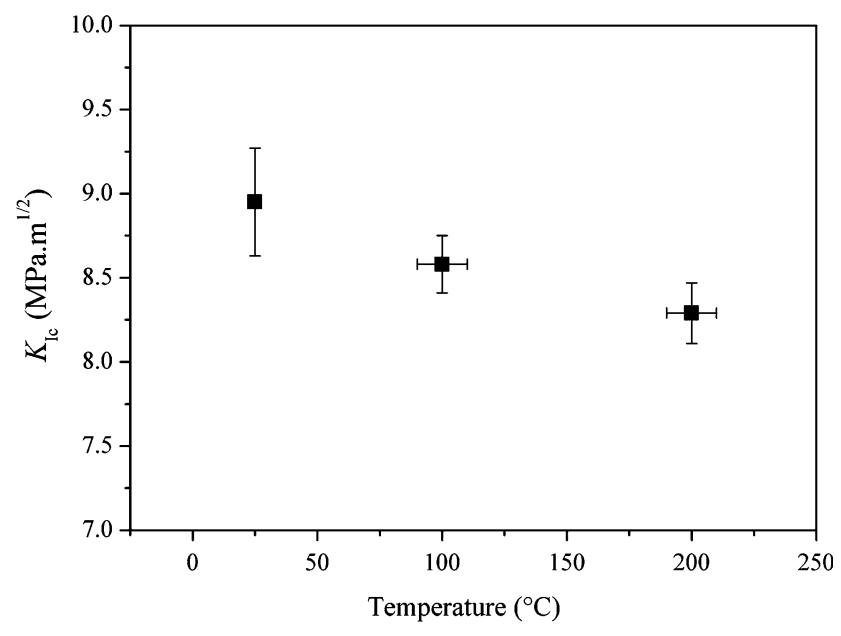

Fig. 3-Plane strain fracture toughness $\left(K_{\mathrm{Ic}}\right)$ values measured for the as-cast 7050 alloy from room temperature to $200{ }^{\circ} \mathrm{C}$.

behavior is observed above $350{ }^{\circ} \mathrm{C}$ in rheological torsion tests. Deviation from the real Young's modulus value is even higher in Gleeble results, which is caused by the different stiffness of the machine relative to the sample. The high strain rate torsion tests, on the other hand, are in good agreement with the simulation results, which were eventually applied in the model.

In order to assess the critical crack size leading to catastrophic failure, plane strain fracture toughness tests were performed from room temperature to $200{ }^{\circ} \mathrm{C}$ following ASTM-E399 regulations. The samples prepared based on the dimensional proportions mentioned in the standard were locally polished around the chevron notch to be able to follow and accurately measure the fatigue crack length. Samples were then fatigue precracked at room temperature to reach the total crack length of $15 \mathrm{~mm}$ (including the chevron notch length of $13 \mathrm{~mm}$ ). The loading rate was chosen in such a way to keep the stress intensity within the range of 0.55 to $2.75 \mathrm{MPa} \cdot \mathrm{m}^{1 / 2} \cdot \mathrm{s}^{-1}$. At higher temperatures, samples were first covered with a ceramic coating for insulation and preventing a sudden temperature fall (temperature tolerance was $\pm 10{ }^{\circ} \mathrm{C}$ ) and then kept at desired temperatures in an oven for 20 minutes. The $K_{\text {Ic }}$ values from room temperature to $200{ }^{\circ} \mathrm{C}$ were then calculated using the load-displacement curves and are presented in Figure 3. As can be seen, there is a slight decrease in $K_{\text {Ic }}$ values with increasing the temperature. However, taking the error values into account, the differences are insignificant. Above $200{ }^{\circ} \mathrm{C}$, plane strain conditions were not valid any more, mainly because of the sudden fall in the yield strength at that temperature $\left(154 \mathrm{MPa}\right.$ at $200{ }^{\circ} \mathrm{C}$ to $73 \mathrm{MPa}$ at $300{ }^{\circ} \mathrm{C}$ ). Thus, the crack tip opening displacement (CTOD) values were calculated based on ASTM-E1820-01 as follows: $25^{\circ} \mathrm{C}$ : $6.4 \pm 1 \mu \mathrm{m} ; \quad 100{ }^{\circ} \mathrm{C}: \quad 7.8 \pm 0.8 \mu \mathrm{m} ; 200{ }^{\circ} \mathrm{C}: 11.7 \pm$ $1.5 \mu \mathrm{m} ; 300{ }^{\circ} \mathrm{C}: 495 \pm 32 \mu \mathrm{m} ; 400{ }^{\circ} \mathrm{C}: 780 \pm 77 \mu \mathrm{m}$ and are demonstrated in Figure 4 in a logarithmic scale. As is obvious, below $200{ }^{\circ} \mathrm{C}$ the material is extremely brittle with CTOD values below $12 \mu \mathrm{m}$ with a sudden increase at $300{ }^{\circ} \mathrm{C}$. Similar trends were observed for the

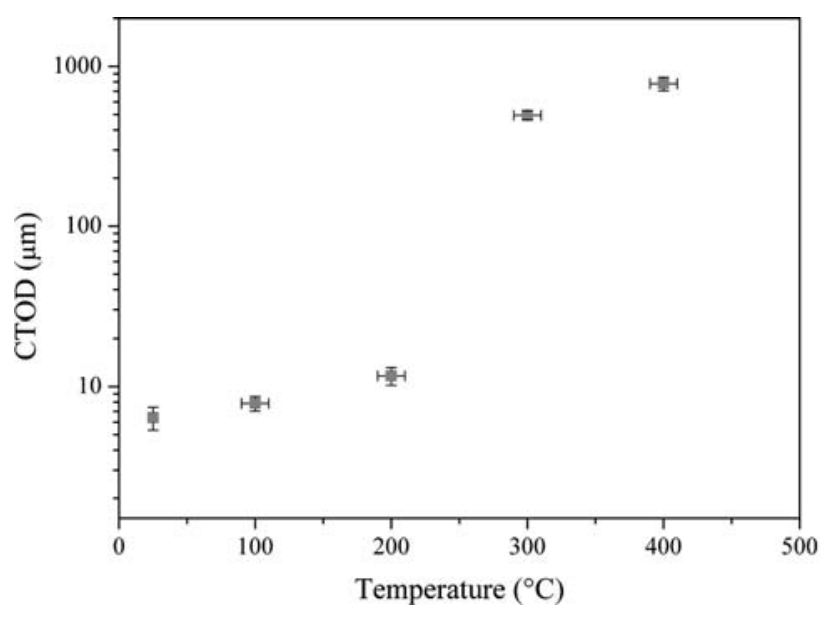

Fig. 4 Crack-tip opening displacement values calculated for the as-cast 7050 alloy from room temperature to $400{ }^{\circ} \mathrm{C}$.

reduction of area in tensile tests ${ }^{[2]}$ and were reported previously by the authors.

\section{SIMULATION RESULTS}

Since cold cracking occurs in the completely solid state and even sometimes at room temperature during the sawing attempt, it is necessary to study the state of stresses not only when the steady state is gained but also when the casting and the water flow are stopped. To achieve this goal, simulations were planned to run for 2800 seconds in the following manner: casting for the first 600 seconds, ramping the casting speed to zero from 600 to 700 seconds, cooling the side walls with water flow from 700 to 1000 seconds, switching off the water from 1000 to 1100 seconds, and air cooling from 1100 to 2800 seconds. It is worth mentioning that at this moment the temperature in the entire billet is between $30{ }^{\circ} \mathrm{C}$ and $60{ }^{\circ} \mathrm{C}$. As the steady-state conditions are reached after 200 seconds of casting simulation for the current billet, 600 seconds of casting would be long enough to investigate the evolution of residual thermal stresses built up during the casting process.

Figures 5(a) through (d) show the contour maps of the four components of residual thermal stresses remaining in the billet after 2800 seconds of simulation. The magnitudes and distribution of stresses remained more or less constant after ceasing the casting and the water flow, except for the upper part of the billet close to the mold and water impingement zone. The stress state during transient as well as steady-state conditions has been reported by the authors elsewhere. ${ }^{[20]}$ Radial (along the $x$-axis) stresses are highly tensile in the center of the billet (with a maximum in the lower part) and reduce in magnitude as we move to the surface (Figure 5(a)). The same trend holds for the axial (along the $z$-axis) and circumferential components of the stress tensor (Figures 5(b) and (c)). The values of the circumferential component of stress are highly compressive at the surface and highly tensile in the center, with a transition 


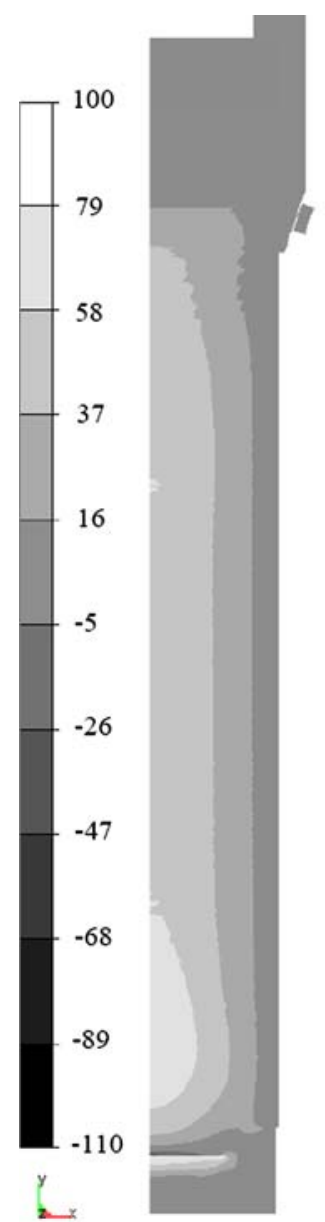

(a) $\sigma_{\mathrm{n}}[\mathrm{MPa}]$

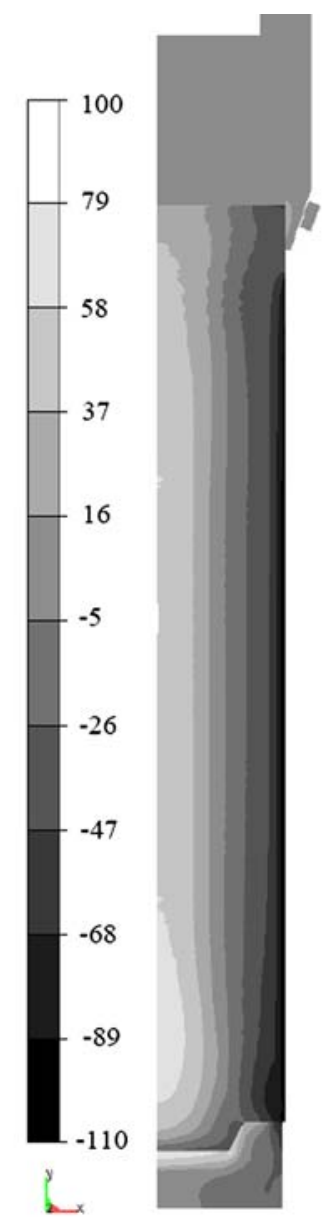

(b) $\sigma_{\pi}[\mathrm{MPa}]$

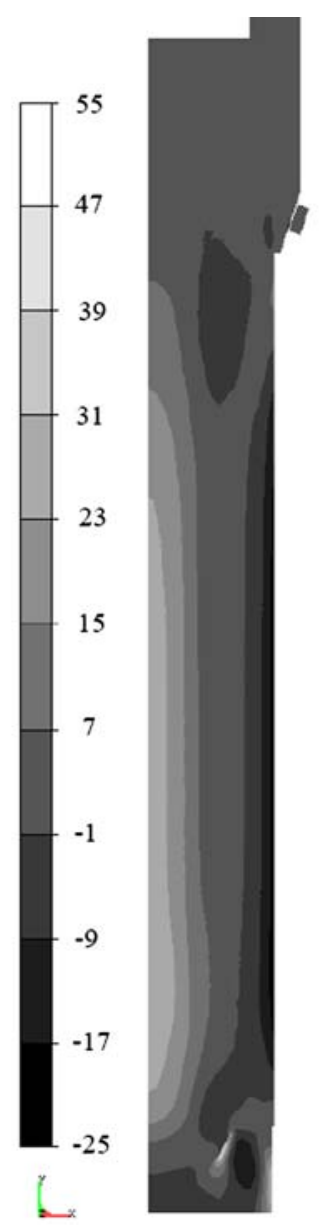

(c) $\sigma_{z z}[\mathrm{MPa}]$

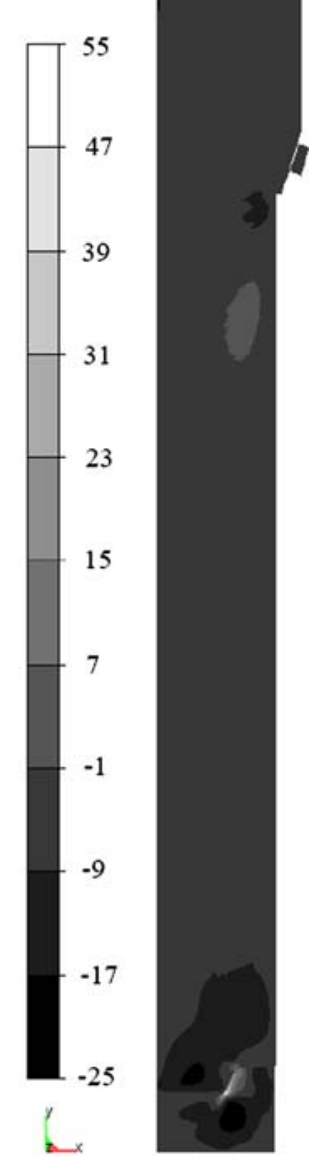

(d) $\sigma_{\mathrm{rz}}[\mathrm{MPa}]$

Fig. 5-Computer simulated residual thermal stresses after 2800 s: $(a)$ radial, $(b)$ circumferential, $(c)$ axial, and $(d)$ shear component.

point in the mid-radius. Shear stress components are mainly small and their maximum negative values appear around the water impingement area and in the lower part of the billet in the vicinity of the bottom block (Figure 5(d)).

Contour maps of the viscoplastic part of the plastic strain are shown in Figures 6(a) through (d). The radial component of the plastic strain is mostly tensile in the lower central part of the billet, decreases in the midradius and increases again as we move to the surface of the billet. In the upper parts of the billet it remains homogenous and relatively low in value, except for the surface of the billet. The circumferential component (Figure 6(b)) appears to be tensile in the bottom center of the billet and by moving to the surface, it turns to compressive with maximum values in the lower right corner. Unlike radial and circumferential components, the axial component of the plastic strain tensor shows negative (compressive) values in the center (with a minimum on top of the bottom block) and by moving to the surface (except for upper part) it converts to tensile (Figure 6(c)). The compressive values of the axial plastic strains in the lower part of the billet seem to be unexpected, taking into account the axial stress component. But this is mainly the consequence of compressive axial viscoplastic strain rate near the solidification front, as explained by Fjaer et al. ${ }^{[10]}$ Shear stress components are mainly small with the most negative values in the lower part of the billet in the vicinity of the bottom block (Figure 6(d)).

In order to examine the occurrence of plastic yield in the billet, contour maps of the hardening parameter $\alpha$, effective stress, and accumulated effective strain were used (Figures 7(a) through 7(c)). In those locations of the billet where the temperature is above $T_{0}$ or no yielding is present $(\alpha=0)$, the total viscoplastic strain is generated by creep, which is the case for the entire center of the billet (Figure 7(a)). A result of strain hardening can be seen in Figure 7(b), where the effective stress at the surface is greater than $100 \mathrm{MPa}$, which is certainly above the 0.2 pct offset yield strength of the 7050 alloy above $200{ }^{\circ} \mathrm{C}$ (Table II). High effective stresses at the surface are either the result of high tensile stresses in the water impingement zone or the high compressive values appearing in lower parts (both in the circumferential direction). After the end of casting, high tensile stresses in the water impingement zone disappear and the stress state at the surface becomes highly compressive, which leads to some plastic deformation but is indeed not critical. The maximum value of the effective viscoplastic strain 


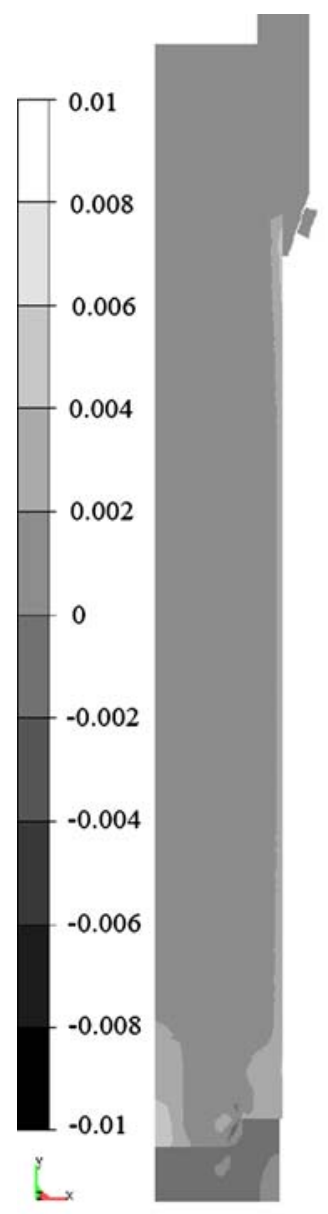

(a) $\varepsilon_{\mathrm{rr}}$

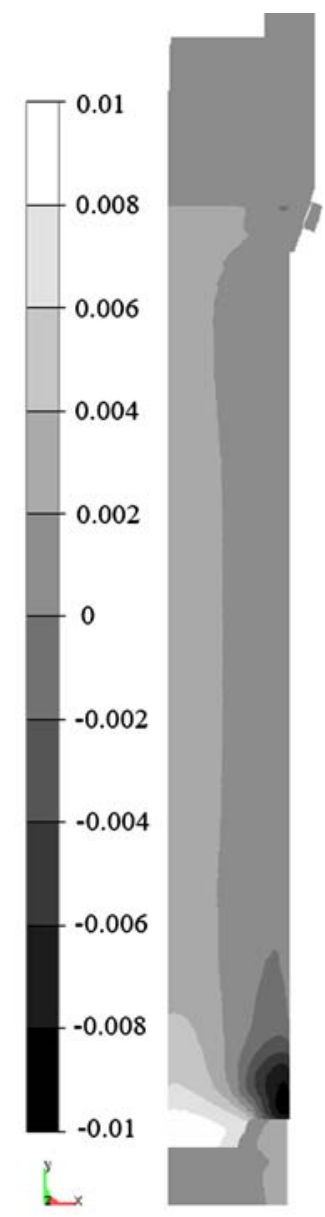

(b) $\varepsilon_{\mathrm{TT}}$

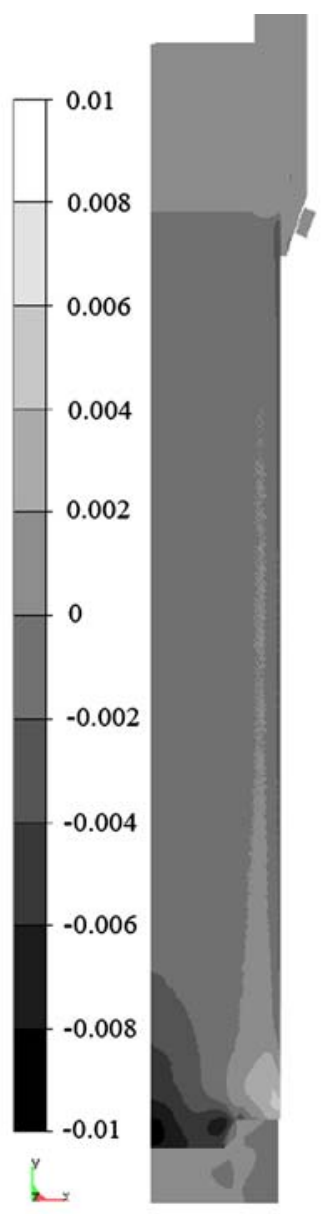

(c) $\varepsilon_{\mathrm{zz}}$

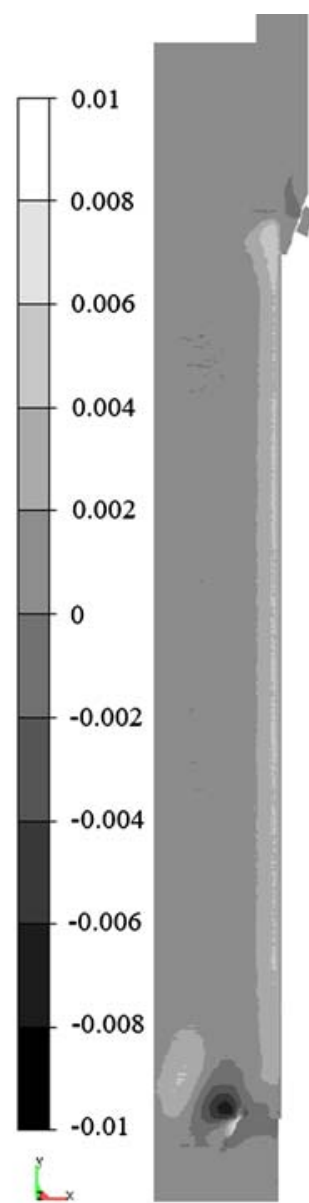

(d) $\varepsilon_{\mathrm{rz}}$

Fig. 6-Computer simulated residual viscoplastic strain after $2800 \mathrm{~s}$ : (a) radial, (b) circumferential, $(c)$ axial, and (d) shear components.

appeared to be 1.26 pet and is observed mainly in the surface of the billet and in the lowest central part on top of the bottom block (Figure 7(c)). The contour map of the largest component of the principal stresses is also shown in Figure 7(d). As can be seen, its maximum value appears in the lower central part of the billet (after 200 seconds of casting (Figure 8(a))). The evolution of the largest component of the principal stresses and its effect on cracking will be discussed in Section $\mathrm{V}$ in more detail.

\section{CRACKING ASSESSMENT IN THE BILLET}

It is possible to assess the cracking probability using the largest component of the principal stresses assuming that it is acting normal to the crack plane and treating the ingot as a semi-infinite medium. ${ }^{[6]}$ Before turning to that point, let us have a look at the evolution of the largest component of the principal stresses in the billet during casting. Having chosen the origin of the coordinate system in the center of the top surface of the bottom block, the following points were taken for stress analysis: surface $(x: 95 \mathrm{~mm}, y: 24 \mathrm{~mm})$, mid-radius $(x$ : $48 \mathrm{~mm}, y: 24 \mathrm{~mm})$, center $\left(x: 1 \times 10^{-5} \mathrm{~mm}, y: 24 \mathrm{~mm}\right)$, and center $+10\left(x: 1 \times 10^{-5} \mathrm{~mm}, y: 34 \mathrm{~mm}\right)$ (this point represents the lowest point in the billet with the maximum principal stress). Figure 8(a) shows the changes of the largest component of the principal stresses with the simulation time for the points mentioned previously, and the corresponding computer simulated cooling curves are shown in Figure 8(b). The principal stress reaches its maximum $(51 \mathrm{MPa})$ at the surface after 73 seconds where the temperature is around $186{ }^{\circ} \mathrm{C}$ (Figure 8(b)). It falls afterward mainly because of the change in the stress mode at the surface from tensile to compressive.

In the center of the billet, on the other hand, the principal stress reaches its maximum value $(73 \mathrm{MPa})$ after 200 seconds and the temperature is $200^{\circ} \mathrm{C}$ (Figure $8(\mathrm{a})$ ). Having reached the steady state, this value falls and remains constant even after ceasing the casting and stopping the water flow. It is also obvious from Figure 8(a) that the maximum in the principal stress value occurs sooner and with a lower value as we move to the surface (except for the initial peak occurring at the surface mainly because of the initial tensile stresses).

As the largest component of the principal stresses reaches its maximum in the center where the temperature is $200{ }^{\circ} \mathrm{C}$, the $K_{\text {Ic }}$ value corresponding to this temperature can be applied to assess the critical crack 


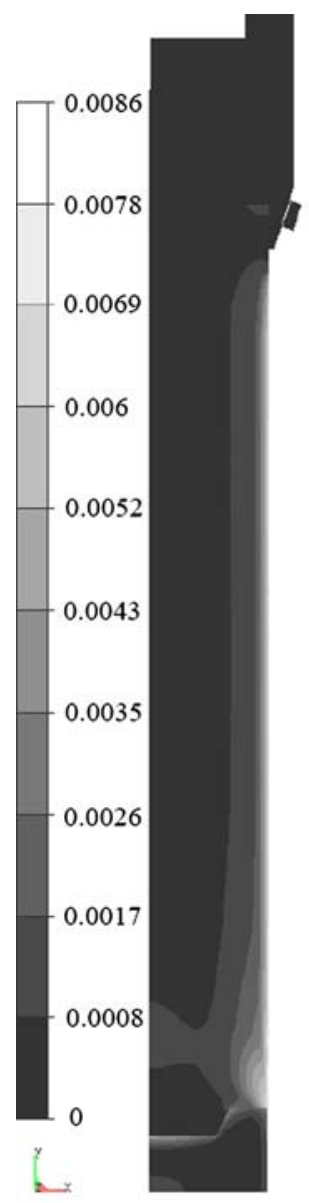

(a) $\alpha$

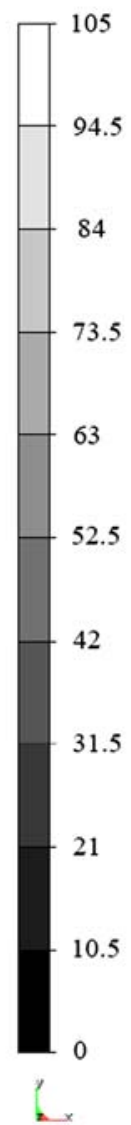

(b) $\sigma_{\text {eff }}[\mathrm{MPa}]$
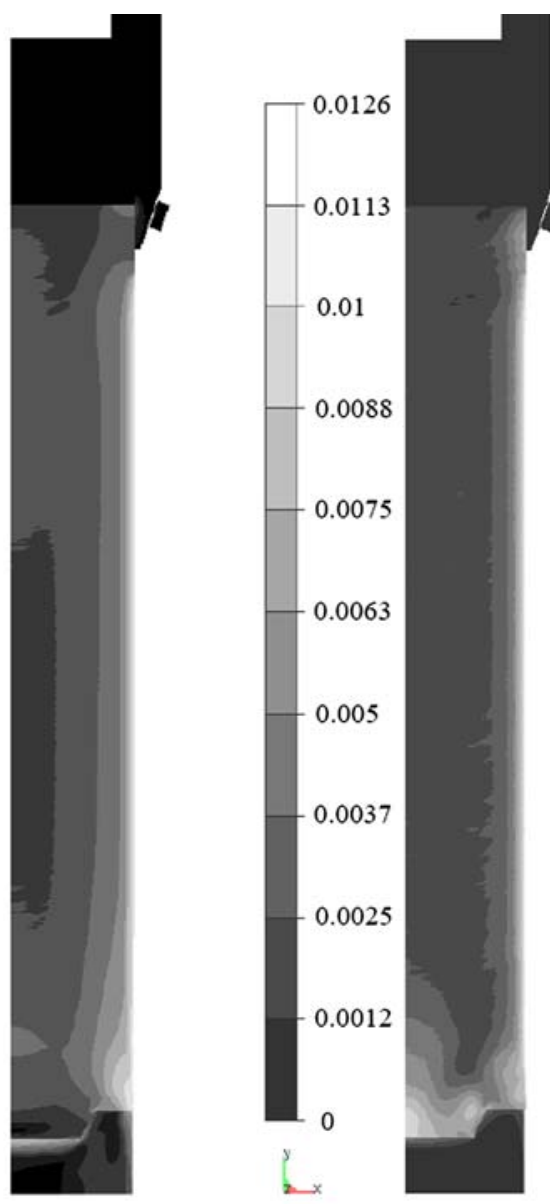

(c) $\varepsilon_{\text {accumulated }}$
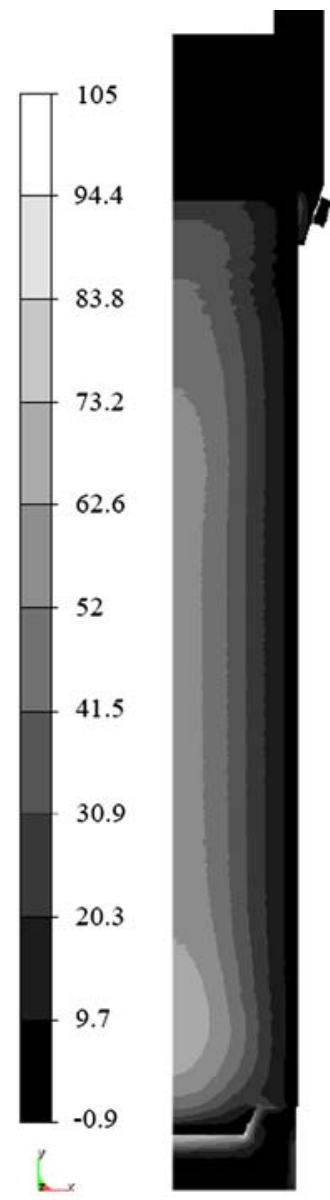

(d) $\sigma_{\mathrm{p}}[\mathrm{MPa}]$

Fig. 7-Investigation of plastic yield and strain hardening using the computer simulated contour maps of: $(a)$ hardening parameter, $(b)$ effective stress, $(c)$ accumulated effective strain, and $(d)$ the largest component of the principal stresses.

size. Following the same procedure for lower temperatures down to the room temperature using the corresponding principal stress will provide us with the critical crack size leading to catastrophic failure in the billet upon cooling. Taking into account casting practice, cracks with different geometries were assumed to be formed either at the surface or in the center. A penny shaped crack (PSC) was chosen for the center and midradius of the billet. The critical crack size for brittle fracture corresponding to this geometry is calculated as follows based on Griffith's analysis: ${ }^{[21]}$

$$
a_{c}=\frac{\pi}{4}\left(\frac{K_{\mathrm{Ic}}}{\sigma}\right)^{2}
$$

At the surface of the billet, the surface breaking semicircular (thumbnail) crack is chosen, for which the critical crack size is related to the $K_{\text {Ic }}$ and nominal stress as follows: ${ }^{[22]}$

$$
a_{c}=\frac{\pi}{(2 \times 1.21)^{2}}\left(\frac{K_{\mathrm{Ic}}}{\sigma}\right)^{2}
$$

Critical crack sizes leading to the catastrophic failure are presented in Figure 9 in the center, center +10 , at the mid-radius, and at the surface of the billet. Since the $K_{\mathrm{Ic}}$ values were only measurable at and below $200{ }^{\circ} \mathrm{C}$, the critical crack sizes were calculated for the moments that the temperature in the billet falls below the mentioned temperature. The critical crack sizes were calculated by applying Eqs. [3] and [4] to the corresponding principal stress values of the mentioned points in the billet (Figure 8(a)) and the $K_{\text {Ic }}$ values (Figure 3). As can be seen in Figure 9, for a PSC, the critical crack size leading to catastrophic failure is minimum for the center, center +10 , and mid-radius when they are at $200{ }^{\circ} \mathrm{C}$, mainly because of the maximum principal stress value reached at this moment. As the temperature falls below $200{ }^{\circ} \mathrm{C}$, the principal stress value decreases a little bit leading to larger critical crack sizes at these points. The cracking probability increases also as we move from the midradius to the center. Maximum probability zone starts from $34 \mathrm{~mm}$ above the bottom block in the positive $y$ direction (the light-gray zone in Figure 7(d)). The smallest critical crack size $(10 \mathrm{~mm})$, which appears at $200{ }^{\circ} \mathrm{C}$, is mainly because of the highest value of the largest component of the principal stresses at this temperature. 


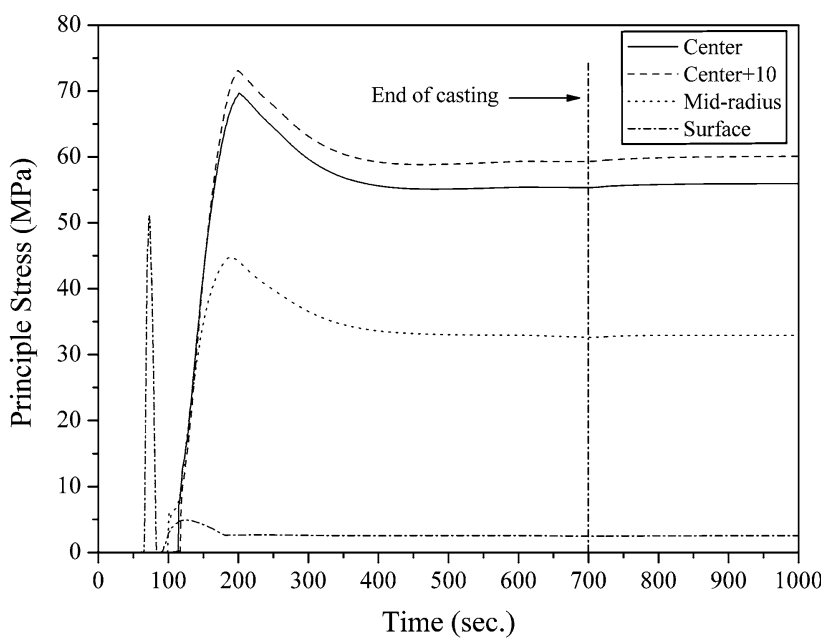

(a)

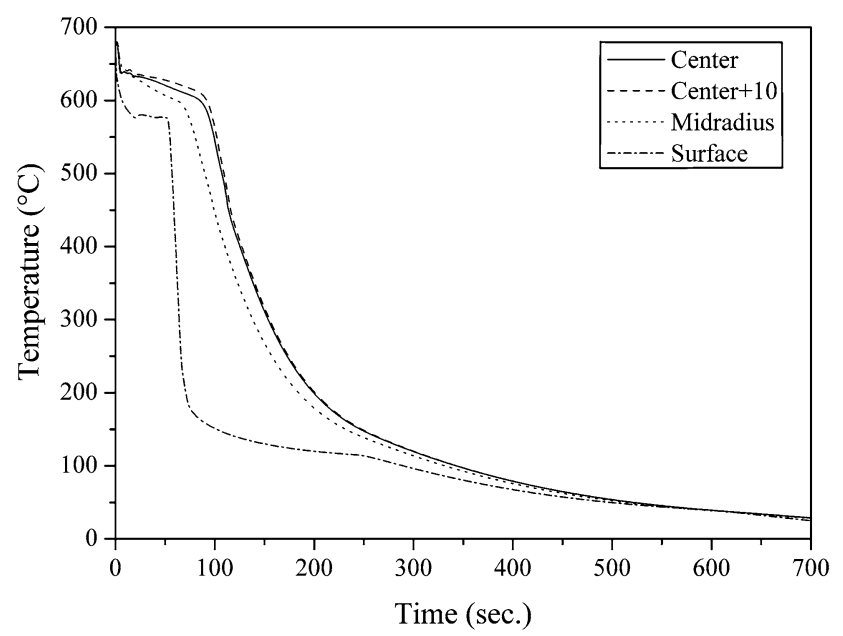

(b)

Fig. 8-(a) Evolution of the largest component of the principal stresses in the center of the billet ( $24 \mathrm{~mm}$ above the bottom block), center +10 ( $34 \mathrm{~mm}$ above the bottom block), mid-radius $(24 \mathrm{~mm}$ above the bottom block) and at the surface with the same height as mid-radius (computer simulation results), $(b)$ computer simulated cooling curves for the points mentioned above.

For the surface of the billet, the maximum principal stress appears after 73 seconds in the water impingement zone where the temperature is around $186{ }^{\circ} \mathrm{C}$. At this temperature and under described stress conditions, the critical crack size was calculated $14.1 \mathrm{~mm}$ for a thumbnail crack (Figure 9). By moving away from the water impingement zone during the casting, the stress at the surface turns to compressive values and the largest component of the principal stresses turns to negative. This results in very large and not realistic critical crack sizes $\left(5.8 \mathrm{~m}\right.$ at $100{ }^{\circ} \mathrm{C}$ and $6.4 \mathrm{~m}$ at $\left.25^{\circ} \mathrm{C}\right)$, which were not plotted here.

\section{DISCUSSION}

Following the evolution of residual thermal stresses in the DC-cast billet mentioned previously, one learns that

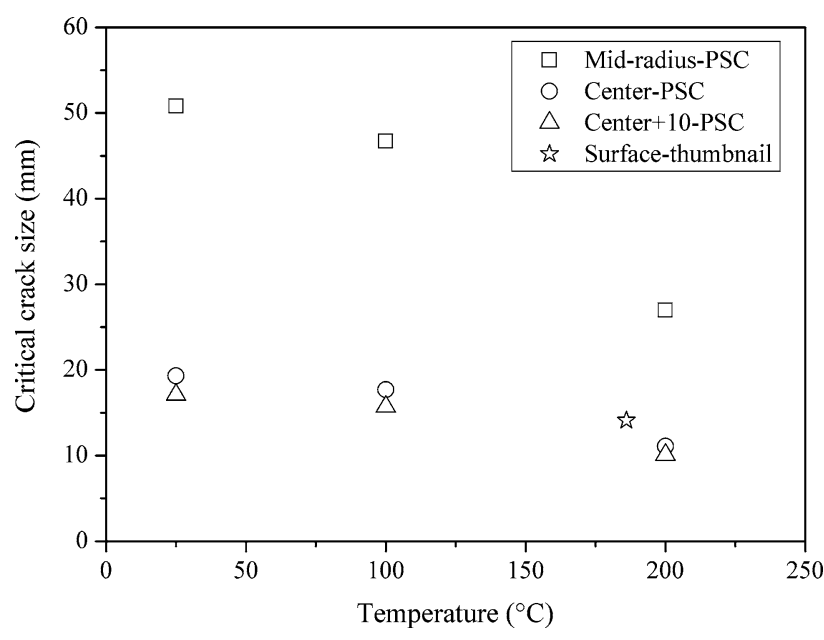

Fig. 9- Critical crack size for a penny shaped crack in the center, center +10 , and mid-radius of the billet.

the stress state in the center of the billet remains tensile for almost the entire casting time except for the very beginning, when it is slightly under compression resulting from the contraction of the surface. At the surface of the billet, on the other hand, stresses are tensile in the water impingement zone, but they turn to compressive upon further cooling. Thus, two critical stages appear during DC casting of high strength aluminum alloys billets of the given size: first at the surface after 73 seconds when high tensile stresses form and second in the center after 200 seconds when the principal stress reaches its maximum value. Large initial tensile stresses at the surface can lead to crack formation in this region, although the compressive stresses formed later may save the billet from failure in this stage. According to fracture mechanics, however, large thumbnail cracks with the critical length of $14.1 \mathrm{~mm}$ can catastrophically propagate in the tensile stress field and result in J-cracks. ${ }^{[7,8,26]}$ (This occurs mainly in slabs where the stress state in the vicinity of the narrow side remains tensile. ${ }^{[23]}$ ) Apparently such cracks do not get the chance to reach such lengths during the short period of the tensile stress occurrence in billets. In the center of the billet, the situation remains always critical especially after $200 \mathrm{sec}-$ onds when the largest component of the principal stresses reaches its maximum value $(73 \mathrm{MPa})$. What makes the situation even more critical is the fact that the material loses its ductility and becomes extremely brittle below $200{ }^{\circ} \mathrm{C}$ (Table II and Figure 4). Under these conditions cracks may initiate or the already initiated ones may propagate up to the critical length of 10 to $17 \mathrm{~mm}$ for PSCs. Initial cracks in the center of the billet may initiate through hot cracking above the solidus temperature and gradually grow in the tensile stress fields in radial, circumferential, or axial directions until they reach the critical length. From this moment on, the material is prone to cold cracking. An example of such cracks can be seen in Figures 10(a) and (b) showing a 7475 DC-cast billet failed through cold cracking. Chemical composition of this billet is mentioned in Table II. Cold cracking has resulted in splitting the billet open in 
Figure 10(a), while in Figure 10(b), the crack has stopped near the surface. As is obvious in Figure 10(a), the macroscopic fracture surface consists of two parts separated by color contrast from each other. The measurement of the width of the narrow bright part at the surface of the billet $(3.4 \mathrm{~mm})$ in Figure 10(a) shows that it is much smaller than the critical crack size $(14.1 \mathrm{~mm})$ predicted by fracture mechanics. On the other hand, the wider part of this zone at the surface closer to the bottom of the billet is more than $20 \mathrm{~mm}$ in width (longer than the calculated critical length of $14.1 \mathrm{~mm})$. So the crack might be initiated at the surface in the beginning of casting, but did not propagate during casting because of the compressive stress (Figure 5(b)). During sawing attempt the compressive stresses were relived and the existing crack of critical size propagated catastrophically from the bottom and surface of the billet. Figure 10(b) shows another case when the crack has propagated along the radial direction, mainly because of the high circumferential and radial components of the stress tensor (Figures 5(a) and (b)). The
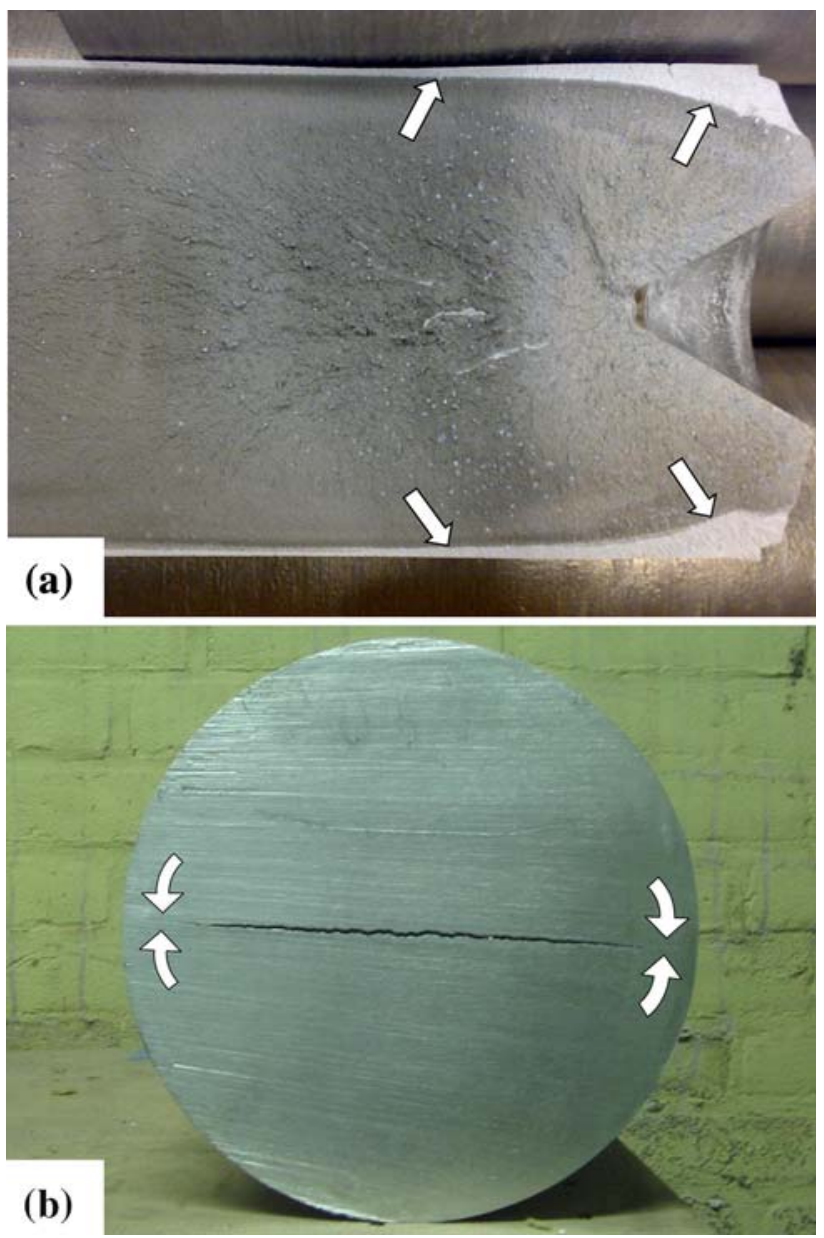

Fig. 10 - Photos showing cold cracks in 200-mm 7475 DC-cast billet: (a) view of the billet split open during sawing attempts, showing two parts of fracture surface separated by a color contrast and $(b)$ cross section of the billet with a cold crack with arrows showing the direction of compressive circumferential stresses tending to cease the crack. crack stopped near the surface when the elastic energy of the tensile stresses was released upon crack propagation. In the meantime, the strong compressive circumferential component of the stress (Figure 5(b)) at the surface protects the billet from splitting open. Removing this protective compressive-stressed layer during the sawing attempt in cast halls makes the billet defenseless and provides a chance for the existing micro-cracks to propagate catastrophically. It is worth mentioning that cracks mainly propagate along the grain boundaries and interdendritic spaces where the brittle intermetallics (non-equilibrium eutectic phases) are located (Figure 11(a)). ${ }^{[2,24,25]}$ As a result of this, they follow a riverlike pattern and may not eventually get aligned normal to the largest component of the principal stresses. The crack may even stop at the matrix, where the plasticity is high enough to cease the brittle fracture (Figure 11(b)). Thus, the final shape and microstructural features of the micro-cracks are the main factors

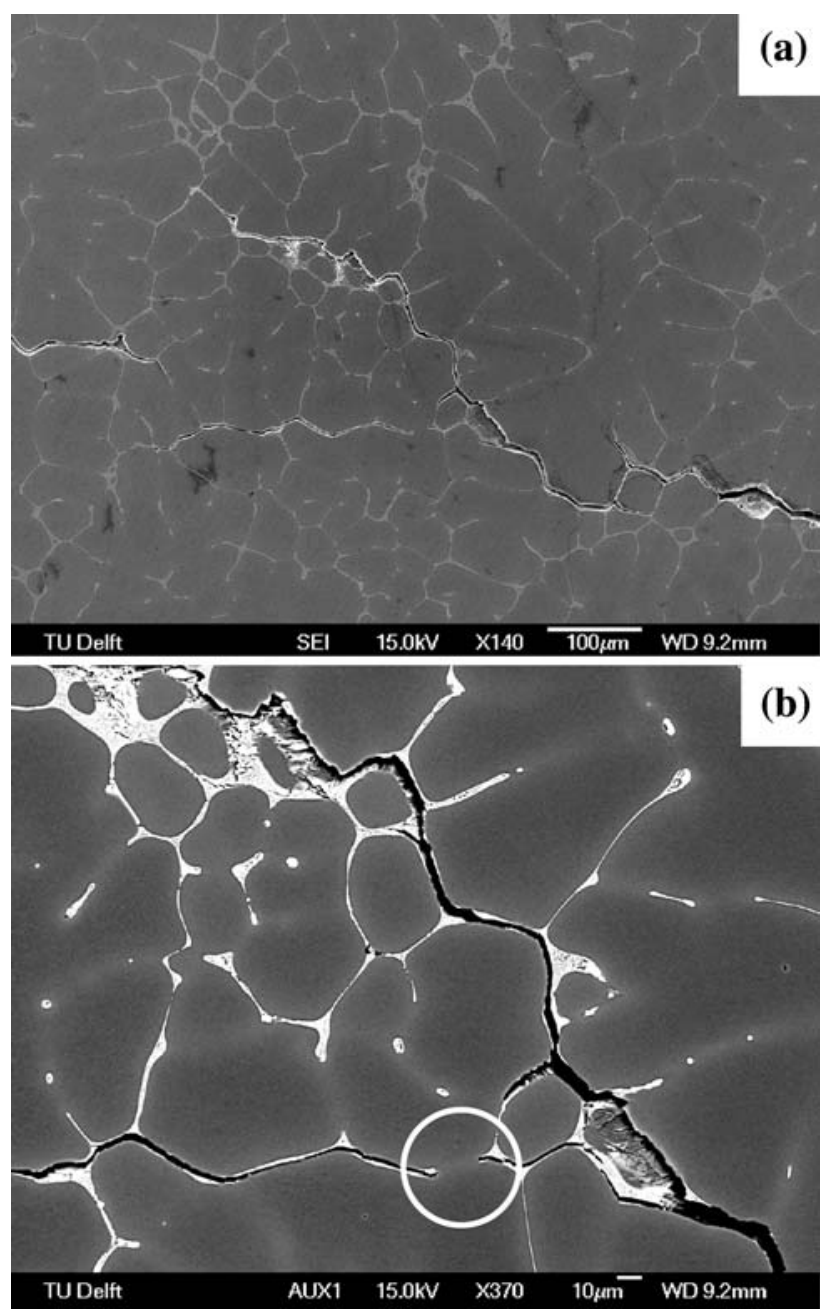

Fig. 11-Micrographs showing the propagation of micro-cracks: (a) a hot crack formed during the solidification in the center of a 7050 DC-cast billet with a diameter of $225 \mathrm{~mm}$, this crack did not reach the critical conditions for catastrophic failure, so the billet remained sound, SEM, and $(b)$ the same crack showing propagation through intermetallics, electron backscattered image. The arrow shows how the cracks stop as they reach the matrix. 
that make cold cracking an unpredictable phenomenon. In fact, the triaxial stress state in the billet and the preferable propagation path along the grain boundaries and interdendritic spaces might drive the micro-cracks in such a way that none of them get eventually exactly aligned normal to the largest component of the principal stresses nor reach the critical length for catastrophic propagation. In this case, no cold cracking occurs.

\section{CONCLUDING REMARKS}

Thermomechanical simulation of residual thermal stresses in an AA7050 DC-cast billet revealed that large tensile stresses might form in the water impingement zone at the surface and in the center of the billet. Such stresses can result in formation of micro-cracks especially in the center of the billet, where all components of the stress tensor are tensile. After 200 seconds, the largest component of the principal stresses reaches its maximum in the center of the billet, where the material is extremely brittle because of the fall in the ductility at that temperature. Since the magnitude and distribution of the residual thermal stresses would not change unless the billet is annealed or cut, the billet remains vulnerable to cold cracking after 200 seconds of casting. Any micro-crack or defect formed during or after the solidification may propagate due to the tensile stress field especially in the center of the billet and reach the critical value for catastrophic failure. Large compressive circumferential stresses at the surface may save the billet from failure in the initial stage. Removing the protective outer shell (with large compressive stresses) of the billet during, e.g. sawing results in changing the distribution of the stresses in the billet and provides a chance for propagation of existing defects or micro-cracks. Our results show that cold cracking of high strength aluminum alloys requires the presence in the structure of defects with a considerable length. Such defects can be micro-cracks at the interface of matrix with intermetallics, ${ }^{[2]}$ chain of porosities or inclusions, or hot tears formed in the solidification range, which requires further investigation. However, it is worth mentioning that the complexity of the microstructure in the as-cast condition and the geometry of defects play an important role in ceasing the crack or leading to catastrophic failure.

\section{ACKNOWLEDGMENTS}

This research was carried out under Project No. 05237 in the framework of the Research Program of the Materials Innovation Institute (www.m2i.nl), former Netherlands Institute for Metals Research. Support and fruitful discussions with Dr. W. Boender (Corus R\&D) are appreciated. Another important basis of the present article is given by comments received from Messrs. D. Mortensen and $\mathrm{H}$. Fjaer and Dr. A. Ten Cate. The authors especially thank Dr. A. Ten Cate for the preparation of the geometry and mesh simulation files. The cooperation and remarks offered by Drs. T. Riemslag and M. Jansen in performing $K_{\text {Ic }}$ tests are also appreciated.

\section{REFERENCES}

1. B. Hannart, F. Ciaalti, and R. van Schalkwijk: in Light Metals, U. Mannweiler, ed., TMS, Warrendale, PA, 1994, pp. 879-87.

2. M. Lalpoor, D.G. Eskin, and L. Katgerman: Mater. Sci. Eng., A, 2008, vol. 497, pp. 186-94.

3. J.M. Drezet and M. Rappaz: in Light Metals, J. Evans, ed., TMS, Warrendale, PA, 1995, pp. 941-50.

4. K.-M. Chang and B. Kang: J. Chin. Inst. Eng., 1999, vol. 22, pp. $27-42$.

5. H.G. Fjaer and A. Mo: in Light Metals, C.M. Bickert, ed., TMS, Warrendale, PA, 1990, pp. 945-50.

6. W. Boender, A. Burghardt, E.P. van Klaveren, and J. Rabenberg: in Light Metals, A.T. Tabereaux, ed., TMS, Warrendale, PA, 2004, pp. 679-84.

7. O. Ludwig, J.-M. Drezet, B. Commet, and B. Heinrich: in Modeling of Casting, Welding and Advanced Solidification Processes, MCWASP XI, C.-A. Gandin and M. Bellet, eds., TMS, Warrendale, PA, 2006, pp. 185-92.

8. W. Boender and A. Burghardt: Proc. 5th Decennial Int. Conf. on Solidification Processing, H. Jones, ed., University of Sheffield, Sheffield, United Kingdom, 2007, pp. 714-18.

9. J. Wan, H.M. Lu, K.M. Chang, and J. Harris: in Light Metals, B. Welch, ed., TMS, Warrendale, PA, 1998, pp. 1065-71.

10. K.-M. Chang, H.-M. Lu, and J. Wan: 2nd Int. Conf. on Quenching and Control of Diffusion, J.F. Harris, ed., ASM INTERNATIONAL, Materials Park, OH, 1996, pp. 341-45.

11. H.G. Fjaer and A. Mo: Metall. Trans. B, 1990, vol. 21B, pp. 1049 61.

12. E.E. Madsen and G.E. Fladmark: in Numerical Solution of Partial Differential Equations, G.E. Fladmark and J.G. Gram, eds., D. Reidel Publishing Company, Dordrecht, The Netherlands, 1973, pp. 223-40.

13. E.E. Madsen: in Numerical Methods in Thermal Problems, R.W. Lewis and K. Morgan, eds., Pineridge Press Limited, Swansea, United Kingdom, 1979, pp. 81-89.

14. H. Fossheim and E.E. Madsen: in Light Metals, W.S. Peterson, ed., TMS-AIME, Warrendale, PA, 1979, pp. 695-720.

15. E.K. Jensen and W. Schneider: in Light Metals, C.M. Bickert, ed., TMS-AIME, Warrendale, PA, 1990, pp. 937-43.

16. M. Lalpoor, D.G. Eskin, and L. Katgerman: Proc. 12th Intern. Conf. on Fracture, Ottawa, National Research Council of Canada, 2009 (CD), pp. 1-9.

17. B. Magnin, L. Katgerman, and B. Hannart: Modeling of Casting, Welding and Solidification Process, MCWASP VII, M. Cross and J. Campbell, eds., TMS, Warrendale, PA, 1995, pp. 303-10.

18. C.L. Martin, O. Ludwig, and M. Suéry: Mater. Sci. Forum, 2002, vols. 396-402, pp. 265-70.

19. J.G. Kaufman: Properties of Aluminum Alloys; Tensile, Creep, and Fatigue Data at High and Low Temperatures, ASM INTERNATIONAL, Materials Park, OH, 2002, p. 207.

20. M. Lalpoor, D.G. Eskin, and L. Katgerman: Proc. Thermec 2009, Trans Tech Publications Ltd, Zürich, in press.

21. H. Tada, P.C. Paris, and G.R. Irwin: The Stress Analysis of Cracks Handbook, 3rd ed., ASME, New York, NY, 2000, Sect. 24.1, p. 342.

22. D.P. Rooke and D.J. Cartwright: Compendium of Stress Intensity Factors, Her Majesty's Stationery Office, London, 1976, Sect. 4.1 .5 , pp. $278-80$.

23. V.A. Livanov: in Aluminum Alloys, A.F. Belov and G.D. Agarkov, eds., Oborongiz, Moscow, 1955, pp. 128-68.

24. J. B. Hess: Metall. Trans. A, 1983, vol. 14A, pp. 323-27.

25. S. Benum, D. Mortensen, H. Fjaer, H.-G. Øverlie, and O. Reiso: in Light Metals, W. Schneider, ed., TMS, Warrendale, PA, 2002, pp. 967-74.

26. R.K. Paramatmuni, K.M. Chang, B.S. Kang, and X. Liu: Mater. Sci. Eng. A, 2004, vol. 379, pp. 293-301. 